\title{
A ABORDAGEM SÓCIO-HISTÓRICA COMO ORIENTADORA DA PESQUISA QUALITATIVA
}

\author{
MARIA TERESA DE ASSUNÇÃO FREITAS \\ Faculdade de Educação da Universidade Federal de Juiz de Fora \\ mtl@acessa.com
}

\begin{abstract}
RESUMO
O artigo analisa as perspectivas abertas pela abordagem sócio-histórica para a investigação qualitativa no âmbito das ciências humanas, apoiando-se nas idéias de Vygotsky, Luria e Bakhtin. Aponta que uma forma outra de fazer ciência, envolvendo a arte da descrição complementada pela explicação, pode ser encontrada na pesquisa qualitativa desenvolvida a partir de uma orientação sócio-histórica. Enfatiza nessa abordagem a compreensão dos fenômenos a partir de seu acontecer histórico no qual o particular é considerado uma instância da totalidade social. A pesquisa é vista como uma relação entre sujeitos, portanto dialógica, na qual o pesquisador é uma parte integrante do processo investigativo. Essas idéias têm implicações nas características processuais e éticas do fazer pesquisa em Ciências Humanas que se refletem na relação pesquisador-pesquisado, nos próprios instrumentos utilizados e na análise de dados. Apresenta um relato descritivo do processo metodológico desenvolvido em uma pesquisa qualitativa de cunho sócio-histórico.

PESQUISA QUALITATINA - CIÊNCIAS HUMANAS
\end{abstract}

\section{ABSTRACT}

This article analyzes the vistas opened up by a socio-historical approach to qualitative research in the realm of the social sciences, based in the ideas of Vygotsky, Luria and Bakhtin. It points to another way of doing science, involving the art of description complemented by explication, which can be found in qualitative research developed on the basis of a socio-historical orientation. This approach emphasizes understanding phenomena based on the historical context of events in which the particular is seen as just an instance of the social totality. Research is seen as the relationship among subjects and is therefore one of dialogue, where the researcher is an integral part of the investigative process. These ideas have implications for the procedural and ethical aspects of social science research which are reflected in the relationship between researcher and researched, both in the very instruments use and in the analysis of data. It presents a descriptive report of the methodological process developed in a qualitative study of a socio-historical nature.

QUALITATIVE RESEARCH - HUMAN SCIENCES

Texto baseado na comunicação apresentada no Primeiro Painel Interinstitucional de Investigação Qualitativa - I PIIQ -, na Faculdade de Educação da Universidade Federal de Juiz de Fora - UFJF -, Minas Gerais, em agosto de 200I. 


\section{ABORDAGEM SÓCIO-HISTÓRICA E PESQUISA}

A perspectiva sócio-histórica, tendo o materialismo histórico-dialético como pano de fundo, expressa em seus métodos e arcabouço conceitual as marcas de sua filiação dialética. Analisando a produção de autores sócio-históricos como Vygotsky, Bakhtin e Luria, percebo como a sua abordagem teórica pode fundamentar o trabalho de pesquisa em sua forma qualitativa, imprimindo-lhe algumas características próprias. A perspectiva sócio-histórica baseia-se na tentativa de superar os reducionismos das concepções empiristas e idealistas. Isso fica evidente no que Vygotsky (I 896-1934) assinala como a "crise da psicologia" de seu tempo, que se debate entre modelos que privilegiam ora a mente e os aspectos internos do indivíduo, ora o comportamento externo. Procura desse modo construir o que chama de uma nova psicologia que deve refletir o indivíduo em sua totalidade, articulando dialeticamente os aspectos externos com os internos, considerando a relação do sujeito com a sociedade à qual pertence. Assim, sua preocupação é encontrar métodos de estudar o homem como unidade de corpo e mente, ser biológico e ser social, membro da espécie humana e participante do processo histórico. Percebe os sujeitos como históricos, datados, concretos, marcados por uma cultura como criadores de idéias e consciência que, ao produzirem e reproduzirem a realidade social, são ao mesmo tempo produzidos e reproduzidos por ela (Freitas, 1996).

Enquanto Vygotsky procura essa solução no campo psicológico, Bakhtin ( 895 1975), enfrentando as teorias do fenômeno lingüístico, critica também as posições empíricas e idealistas do que denomina de objetivismo abstrato e subjetivismo idealista e propõe, em sua perspectiva dialógica, o estudo da língua em sua natureza viva e articulada com o social pela interação verbal.

Analisando uma obra de Luria (1983), companheiro de Vygotsky, verifica-se também toda uma preocupação em encontrar um método de pesquisa compatível com este homem concreto e social. Justificando sua opção de trabalho, Luria comenta que, em sua época, a ciência podia ser dividida em duas categorias: a clássica e a romântica. Identifica a ciência clássica como aquela que focaliza os eventos de maneira fragmentada, concentrando-se em suas partes, em seus elementos isolados. Desta forma, a realidade viva fica reduzida a esquemas áridos e abstratos, o que bem se expressa na famosa frase de Goethe: "Cinzenta é a teoria, verde é a árvore dourada da vida”. Luria observa que, em contrapartida, a ciência romântica não segue o reducionismo dos clássicos, nem subdivide a realidade viva. Para ela é importante preservar na íntegra a variadíssima riqueza da vida, da realidade dos eventos concretos. A ciência romântica, assim, esforçava-se por ascender a uma compreen- 
são científica que não perdesse essas conotações de realidade viva e variada. Luria comenta que a ciência romântica, no entanto, apresenta limitações, escapando-Ihe muitas vezes uma análise racional e paciente que é substituída por impressões intuitivas. Assim compreende que a solução encontrada por Vygotsky em relação à crise da psicologia, ou seja, conservar a concretude do fenômeno estudado, sem ficar nos limites da mera descrição, ou sem perder a riqueza da descrição e avançar para a explicação, deve ser também uma das metas da pesquisa. Considerando que o que faz da atividade psíquica uma atividade psíquica é a sua significação, Bakhtin (1988) afirma que o objetivo da psicologia não pode se restringir a explicar os fenômenos pela sua causalidade, mas que deve se preocupar sobretudo em descrevê-los. Nisso apóia-se em Dilthey, para quem somente uma psicologia descritiva e explicativa pode servir de base às ciências humanas. Apesar de se reportar a Dilthey e considerar o seu valor pela importância dada à significação e aos aspectos descritivos interpretativos, Bakhtin reconhece a base idealista de seu pensamento, que não leva em conta o caráter social do signo. Vê aí a sua limitação: a não-compreensão do vínculo indispensável entre signo e significação. $O$ signo, em Dilthey, serve apenas para expressar a vida interior, privando o mundo material de todo o sentido e significação, dando primazia a um espírito (sujeito) fora do tempo e do espaço. Ora, para Bakhtin, o signo é um fenômeno do mundo exterior, e sua realidade é totalmente objetiva. Assim, um signo não só reflete e refrata a realidade, como tem uma encarnação material. Nesse sentido "a própria consciência só pode surgir e se afirmar como realidade mediante a encarnação material em signos" (1988, p.33).

Pode-se perceber que as idéias de Vygotsky, Luria e Bakhtin procuram realizar o objetivo clássico de focalizar os fatos, mas sem perder de vista a meta romântica de conservar toda a riqueza do objeto. Luria ( I 983) comenta que Marx descreve esse processo com a singular expressão: ascender ao concreto. As palavras de Luria expressam a sua convicção de que a abordagem científica tradicional quantitativa é fundamentalmente limitada com respeito à vida. Para ele a ciência tem de ter algo mais, um complemento indispensável: a arte tem de entrar na ciência, na qualidade de arte da descrição.

Na mesma linha de pensamento, Bakhtin (1985), em seu último texto escrito, "Por uma metodologia das ciências humanas"', é provocador de uma reflexão

I. Este é o título da edição em espanhol do qual faço uma tradução livre: "Hacia una metodologia de las ciencias humanas". Considero essa versão em espanhol mais fiel ao pensamento do autor do que a versão em português: "Observações sobre a epistemologia das ciências humanas". 
inspiradora de uma nova atitude em relação à pesquisa. Nele, Bakhtin diz que as ciências humanas não podem, por ter objetos distintos, utilizar os mesmos métodos das ciências exatas. As ciências humanas estudam o homem em sua especificidade humana, isto é, em processo de contínua expressão e criação. Considerar o homem e estudá-lo independentemente dos textos que cria significa situá-lo fora do âmbito das ciências humanas.

Para Bakhtin, não é possível compreender o homem, sua vida, seu trabalho, suas lutas, senão por meio de textos signos criados ou por criar. Nesse sentido o homem não pode ser estudado como um fenômeno da natureza, como coisa. A ação física do homem precisa ser compreendida como um ato, porém, este ato não pode ser compreendido fora de sua expressão "sígnica", que é por nós recriada.

Não perguntamos à natureza e a natureza não nos contesta. Perguntamos a nós mesmos e organizamos de uma maneira determinada a observação ou o experimento para obter a resposta. Estudando o homem em todas as partes buscamos e encontramos signos e tratamos de compreender seu significado. (1985, p.305, tradução nossa)

Nas ciências humanas, portanto, ao se trabalhar com a interpretação das estruturas simbólicas, faz-se necessário ir à infinitude dos sentidos simbólicos. E é por isso que não se pode pretender, nas ciências humanas, chegar à cientificidade própria das ciências exatas. Essa interpretação dos sentidos é profundamente cognoscitiva: "há que se reconhecer que a simbologia não é uma forma não científica do conhecimento, senão uma forma outra do conhecimento que tem suas leis internas e seus critérios de exatidão" ( 1985, p.382, tradução nossa).

Nas ciências exatas, o pesquisador encontra-se diante de um objeto mudo que precisa ser contemplado para ser conhecido. $\bigcirc$ pesquisador estuda esse objeto e fala sobre ele ou dele. Está numa posição em que fala desse objeto mas não com ele, adotando, portanto, uma postura monológica. Já nas ciências humanas, seu objeto de estudo é o homem, "ser expressivo e falante". Diante dele, o pesquisador não pode se limitar ao ato contemplativo, pois encontra-se perante um sujeito que tem voz, e não pode apenas contemplá-lo, mas tem de falar com ele, estabelecer um diálogo com ele. Inverte-se, desta maneira, toda a situação, que passa de uma interação sujeito-objeto para uma relação entre sujeitos. De uma orientação monológica passa-se a uma perspectiva dialógica. Isso muda tudo em relação à pesquisa, uma vez que investigador e investigado são dois sujeitos em interação. $\bigcirc$ homem não pode ser apenas objeto de uma explicação, produto de uma só cons- 
ciência, de um só sujeito, mas deve ser também compreendido, processo esse que supõe duas consciências, dois sujeitos, portanto, dialógico.

As ciências exatas representam uma forma monológica do conhecimento: o intelecto contempla a coisa e se expressa sobre ela. Aqui somente existe um sujeito, o cognoscitivo (contemplativo) e falante (enunciador). O que se lhe opõe é tão-somente uma coisa sem voz. Qualquer objeto do conhecimento (inclusive o homem) pode ser percebido e compreendido como coisa. Porém um sujeito como tal não pode ser percebido nem estudado como coisa, uma vez que sendo sujeito não pode, se continua sendo-o, permanecer sem voz; portanto seu conhecimento só pode ter caráter dialógico. (Bakhtin, 1985, p.383, tradução nossa)

Essa atitude fundamentadora da pesquisa também pode ser observada em Vygotsky, ao considerar que todo conhecimento é sempre construído na inter-relação das pessoas. Produzir um conhecimento a partir de uma pesquisa é, pois, assumir a perspectiva da aprendizagem como processo social compartilhado e gerador de desenvolvimento.

Essa proposição metodológica é coerente com toda sua teoria dialética de compreensão dos fenômenos humanos. Partindo da premissa básica de que as funções mentais superiores são constituídas no social, em um processo interativo possibilitado pela linguagem e que antecede a apropriação pessoal, Vygotsky também vê a pesquisa como uma relação entre sujeitos, relação essa que se torna promotora de desenvolvimento mediado por um outro. Sua posição tem importantes conseqüências para a pesquisa, em seus próprios experimentos e nos de seus colaboradores: é possível perceber a mediação do pesquisador provocando alterações de comportamento que possibilitam a compreensão de seu desenvolvimento. Seus estudos sobre o desenvolvimento dos conceitos na criança revelam como a palavra mediadora do adulto influi no próprio processo de formação de conceitos. Nos diálogos de Luria (1990) com seus sujeitos, nas pesquisas efetuadas na Ásia Central, e também nos seus experimentos sobre a construção da escrita em crianças, percebe-se o pesquisador desafiando o sujeito, questionando suas respostas, o que possibilita entrever o comportamento afetado pela interferência de uma outra pessoa e também observar os processos psicológicos em sua dinâmica de transformação (Oliveira, 1999).

O pesquisador, portanto, faz parte da própria situação de pesquisa, a neutralidade é impossível, sua ação e também os efeitos que propicia constituem elementos de análise. Bakhtin contribui para complementar essas idéias afirmando que o critério que se busca numa pesquisa não é a precisão do conhecimento, mas a 
profundidade da penetração e a participação ativa tanto do investigador quanto do investigado. Disso também resulta que o pesquisador, durante o processo de pesquisa, é alguém que está em processo de aprendizagem, de transformações. Ele se ressignifica no campo. $\bigcirc$ mesmo acontece com o pesquisado que, não sendo um mero objeto, também tem oportunidade de refletir, aprender e ressignificar-se no processo de pesquisa. Bakhtin e Vygotsky tornam o processo de pesquisa um trabaIho de educação, de desenvolvimento. E isso fica bem explicitado nas palavras de Oliveira:

É interessante observar que essa contribuição metodológica de Vygotsky é particularmente importante para a educação. Uma vez que a situação educativa consiste de processos em movimento permanente, a transformação constitui exatamente o resultado desejável desses processos, os métodos de pesquisa que permitem a compreensão dessas transformações são os métodos mais adequados para a pesquisa educacional. (1999, p.63)

Considera-se, com base no que foi exposto, que essa forma outra de fazer ciência, que envolve a arte da descrição complementada pela explicação e que pode ser encontrada na pesquisa qualitativa com enfoque sócio-histórico, realizaria a síntese sonhada por Luria, Vygotsky e Bakhtin.

\section{A RELAÇÃO DO INDIVIDUAL COM O SOCIAL}

Bogdan e Biklen comentam que

...um campo que era anteriormente dominado pelas questões da mensuração, definições operacionais, variáveis, testes de hipóteses e estatística alargou-se para contemplar uma metodologia de investigação que enfatiza a descriçãa, a indução, a teoria fundamentada e o estudo das percepções pessoais. Designamos esta abordagem por Investigação Qualitativa. (1994, p. I I)

Os estudos qualitativos com o olhar da perspectiva sócio-histórica, ao valorizarem os aspectos descritivos e as percepções pessoais, devem focalizar o particular como instância da totalidade social, procurando compreender os sujeitos envolvidos e, por seu intermédio, compreender também o contexto. Adota-se, assim, uma perspectiva de totalidade que, de acordo com André (1995), leva em conta todos os componentes da situação em suas interações e influências recíprocas.

Na pesquisa qualitativa com enfoque sócio-histórico não se investiga em razão de resultados, mas o que se quer obter é "a compreensão dos comportamen- 
tos a partir da perspectiva dos sujeitos da investigação" (Bogdan, Biklen, 1994, p. I 6), correlacionada ao contexto do qual fazem parte. Assim, as questões formuladas para a pesquisa não são estabelecidas a partir da operacionalização de variáveis, mas se orientam para a compreensão dos fenômenos em toda a sua complexidade e em seu acontecer histórico. Isto é, não se cria artificialmente uma situação para ser pesquisada, mas se vai ao encontro da situação no seu acontecer, no seu processo de desenvolvimento.

Vygotsky ( $199 \mid$ |) critica as formas de pesquisas nas quais o pesquisador planeja situações para eliciar respostas a serem examinadas e analisadas. Pesquisas organizadas como experimentos, que procuram evocar o fenômeno em estudo de uma maneira artificial e controlável. Observa que essa estrutura "não pode servir como base para o estudo adequado das formas superiores especificamente humanas, de comportamento" (1991, p.69). Baseando-se na abordagem materialista dialética, acredita que o comportamento humano difere qualitativamente do comportamento animal e que, portanto, deve ser estudado em sua especificidade. Considera que a conduta humana não é apenas o produto da evolução biológica, graças à qual se formou o tipo humano com todas as suas funções psicofisiológicas a ele inerentes, mas também o produto do desenvolvimento histórico e cultural (Vygotsky, 1996). Assim, ao se estudar o homem é necessário compreendê-lo a partir da interação dialética dessas duas linhas de desenvolvimento: a natural e a cultural. Portanto, os estudos que focalizam o ser humano, buscando compreendê-lo, não podem ser examinados fora dessa relação com o social e nem de uma forma estática.

Vygotsky, mais do que construtor de uma teoria psicológica, foi, antes de tudo, um metodólogo. Como um filósofo da ciência e também um profundo conhecedor da história da psicologia, conseguiu integrar essas duas qualidades contribuindo para a construção de um novo método investigativo.

Para Vygotsky ( | 99|), um método reflete sempre o olhar, a perspectiva que se tem das questões a serem estudadas. Ao considerar que o estudo de situações fundamentalmente novas exige inevitavelmente novos métodos de investigação e análise, olha os problemas humanos na perspectiva da sua relação com a cultura e como produto das interações sociais, percebendo como necessário um reexame dos métodos de pesquisa. Vygotsky ( $199 \mid$ ) propõe, assim, que os fenômenos humanos sejam estudados em seu processo de transformação e mudança, portanto, em seu aspecto histórico. Está, nesse sentido, mostrando que a preocupação do pesquisador deve ser maior com o processo em observação do que com o seu produto. Para tal é necessário ir à gênese da questão, procurando reconstruir a história de sua origem e de seu desenvolvimento. Considera importante a descri- 
ção dos fenômentos que revela seu aspecto exterior, o fenótipo, mas procura um aprofundamento maior da questão ao dizer que esta se completa com a compreensão de seu aspecto interior, de seu genótipo. Focalizar o processo de realização de uma tarefa pode levar à descoberta das estruturas internas de desenvolvimento dos processos psicológicos superiores.

Apoiando-me em Bogdan e Biklen (1994), compreendo que também na investigação qualitativa de cunho sócio-histórico vai-se a campo com uma preocupação inicial, um objetivo central, uma questão orientadora. Para buscar compreender a questão formulada é necessário inicialmente uma aproximação, ou melhor, uma imersão no campo para familiarizar-se com a situação ou com os sujeitos a serem pesquisados. Para tal o pesquisador freqüenta os locais em que acontecem os fatos nos quais está interessado, preocupando-se em observá-los, entrar em contato com pessoas, conversando e recolhendo material produzido por elas ou a elas relacionado. Procura dessa maneira trabalhar com dados qualitativos que envolvem a descrição pormenorizada das pessoas, locais e fatos envolvidos. A partir daí, ligadas à questão orientadora, vão surgindo outras questões que levarão a uma compreensão da situação estudada.

Trabalhar com a pesquisa qualitativa numa abordagem sócio-histórica consiste pois, numa preocupação de compreender os eventos investigados, descrevendo-os e procurando as suas possíveis relações, integrando o individual com o social. Para Luria (1983), seria necessário encontrar uma observação que, aproveitandose das qualidades da ciência romântica, evitasse seus perigos. Assim a observação não se deve limitar à pura descrição de fatos singulares, o seu verdadeiro objetivo é compreender como uma coisa ou acontecimento se relaciona com outras coisas e acontecimentos. Trata-se, pois, de focalizar um acontecimento nas suas mais essenciais e prováveis relações. Quanto mais relevante é a relação que se consegue coIher em uma descrição, tanto mais se torna possível a aproximação da essência do objeto, mediante uma compreensão das suas qualidades e das regras que governam as suas leis. Quanto mais se preservam em uma análise as riquezas das suas qualidades, tanto mais é possível a aproximação das leis internas que determinam sua existência. De fato, só ao colher os traços mais importantes e depois aqueles mais secundários, identificando suas possíveis conseqüências, é que começam a emergir claras as relações que os ligam entre si. $\bigcirc$ objetivo da observação se enriquece, assim, de uma rede de relações relevantes.

A observação é, nesse sentido, um encontro de muitas vozes: ao se observar um evento, depara-se com diferentes discursos verbais, gestuais e expressivos. 
São discursos que refletem e refratam a realidade da qual fazem parte, construindo uma verdadeira tessitura da vida social. $\bigcirc$ enfoque sócio-histórico é que principalmente ajuda o pesquisador a ter essa dimensão da relação do singular com a totalidade, do individual com o social.

A entrevista, na pesquisa qualitativa de cunho sócio-histórico, também é marcada por essa dimensão do social. Ela não se reduz a uma troca de perguntas e respostas previamente preparadas, mas é concebida como um produção de linguagem, portanto, dialógica. Os sentidos são criados na interlocução e dependem da situação experienciada, dos horizontes espaciais ocupados pelo pesquisador e pelo entrevistado. As enunciações acontecidas dependem da situação concreta em que se realizam, da relação que se estabelece entre os interlocutores, depende de com quem se fala. Na entrevista é o sujeito que se expressa, mas sua voz carrega o tom de outras vozes, refletindo a realidade de seu grupo, gênero, etnia, classe, momento histórico e social.

Ao se analisar o material colhido no campo, procurando compreender o que emergiu numa situação de observação ou de entrevista, ou ainda numa análise de artefatos, é que se percebem os pontos de encontro, as similaridades como também as diferenças, a particularidade dos casos. Fonseca assinala a importância de se observarem estes aspectos na análise dos dados de uma pesquisa dizendo:

Mas para tirar conclusões das análises foi preciso situar os sujeitos em um contexto histórico e social. É só ao completar esse movimento interpretativo, indo do particular ao geral, que o pesquisador cria um relato etnográfico. Sem essa contextualização (um tipo de representatividade post ipso facto) o qualitativo não acrescenta grande coisa à reflexão acadêmica. (1999, p. 61)

A contextualização do pesquisador é também relevante: ele não é um ser humano genérico, mas um ser social, faz parte da investigação e leva para ela tudo aquilo que o constitui como um ser concreto em diálogo com o mundo em que vive. Suas análises interpretativas são feitas a partir do lugar sócio-histórico no qual se situa e dependem das relações intersubjetivas que estabelece com os seus sujeitos. É nesse sentido que se pode dizer que o pesquisador é um dos principais instrumentos da pesquisa, porque se insere nela e a análise que faz depende de sua situação pessoal-social. Para Bakhtin (1988), cada pessoa tem um certo horizonte social definido e estabelecido que orienta a sua compreensão e que o coloca diante de seu interculocutor com uma forma própria de relacionamento. A partir dessa situação social, do lugar em que se situa, é que constrói suas deduções, suas moti- 
vações e apreciações. A leitura que faz do outro e dos acontecimentos que o cercam está impregnada do lugar de onde fala e orientada pela perspectiva teórica que conduz a investigação.

Tudo isso dá um tom específico e diferenciador aos estudos qualitativos na abordagem sócio-histórica, que não podem ser percebidos como um encontro de psiques individuais, mas como uma relação de textos com o contexto.

Toda compreensão representa a confrontação de um texto com outros textos [...]. Um texto vive unicamente se está em contato com outro texto. Unicamente no ponto deste contato é que surge uma luz que ilumina atrás e adiante e que insere o texto dado no diálogo. (Bakhtin, 1985, p.384)

\section{PESQUISA COM ADOLESCENTES NA ÓTICA DA PERSPECTIVA SÓCIO-HISTÓRICA}

Para concretizar algumas das idéias apresentadas vou remeter-me a uma pesquisa que se dedicou ao estudo da construção/produção da escrita de adolescentes na Internet².

trabalho foi orientado a partir da questão inicial formulada: compreender como o uso de um instrumento cultural da contemporaneidade, a Internet, está mediando a construção da linguagem escrita de um grupo de estudantes seus usuários e como a escola trabalha em seu interior a construção da escrita.

Conscientes do que afirma Amorim ( 1997), de que só há pesquisa se, desde o início, são formuladas questões que pressupõem uma problemática, distinguindo pergunta e questão e compreendendo que esta só existe no interior de um campo teórico que orienta o rumo da pesquisa, formulamos nossas questões a partir do campo teórico da perspectiva sócio-histórica. Coerentes com essa escolha, indicamos os procedimentos e os instrumentos a serem adotados: a observação, a entrevista e análise de textos escritos pelos adolescentes nas duas situações: Internet e escola. Procuramos atentar para a especificidade dos sujeitos e consideramos que para abordar adolescentes seria importante pensá-los na perspectiva da alteridade,

2. Trata-se da pesquisa desenvolvida no grupo de pesquisa Linguagem, Interação e Conhecimento - LIC -, sob a coordenação de Maria Teresa de Assunção Freitas: "A construção/ produção da escrita na Internet e na escola" (|999-200 I), apoiada pelo Conselho Nacional de Desenvolvimento Científico e Tecnológico - CNPq - e Fundação de Amparo à Pesquisa do Estado de Minas Gerais - Fapemig. 
compreendê-los como um outro pertencente a um lugar social diferente do adulto pesquisador. A abordagem sócio-histórica, ao apontar para uma relação entre sujeitos, sugere que adolescentes precisam ser considerados parceiros dos pesquisadores. Em conseqüência disso, não mais se pesquisa sobre crianças e adolescentes mas se pesquisa com eles suas práticas socioculturais (Souza, Castro, 1997// 998).

Entendendo que na pesquisa qualitativa o pesquisador, além de ser um sujeito participante, é também um sujeito intelectual ativo no curso da investigação (Rey, 1 999), a entrada em campo foi preparada com maior aprofundamento teórico e prático do objeto de estudo em questão. Assim, começamos o trabalho fundamentando nossas idéias para focalizar a proposta da pesquisa: a escrita de adolescentes na Internet.

Foi necessário compreender o que representa a presença dessa nova tecnologia, a Internet, entre nós. Na perspectiva do método dialético de Vygotsky, os fenômenos devem ser estudados em seu processo de mudança, portanto, em sua historicidade. Assim, recuando no passado, visamos acompanhar como foi constituída essa nova forma de leitura e escrita, e compreender oralidade/escrita/impressão/internet numa perspectiva histórica ${ }^{3}$.

Considerou-se a oralidade como a forma de linguagem básica do homem. A sociedade humana primeiramente se formou com a ajuda do discurso oral, mas só mais tarde tornou-se letrada e não em sua totalidade, pois, esse processo aconteceu de forma e em épocas diferentes para os diversos grupos humanos. O surgimento da escrita, uma nova tecnologia, produziu mudanças nas vidas e nos discursos das pessoas, alterando seus modos de pensamento. A imprensa, que se tornou possível graças à invenção de Gutenberg, foi analisada como um fenômeno que reforçou e transformou os efeitos da escrita sobre o pensamento e a expressão. A invenção da técnica da impressão de caracteres alfabéticos tipográficos, no século XV, evidenciou, mais fortemente do que a escrita, que as palavras são coisas, pois são compostas com tipos de metal nos quais as letras são gravadas. Enquanto a escrita reconstituía a palavra oral no espaço visual, a impressão nele se instalou de forma definitiva. Com a impressão alterou-se tanto a forma do texto, que ele se organizou no códex, no livro, como sua apresentação. Surgiram os índices, as páginas de rosto, a distribuição em linhas e parágrafos (Freitas, 2000).

3. Neste artigo, estão apenas indicados rapidamente os estudos empreendidos no grupo de pesquisa sobre a perspectiva histórica. Consideramos que escapa ao objetivo deste artigo um maior detalhamento da questão. Para uma reflexão mais aprofundada, consultar Rocco ( 1999). 
Se assim aconteceu com a invenção da escrita e da imprensa, que mudanças as novas tecnologias da escrita, oportunizadas pelo computador, pela Internet, poderão imprimir em nosso meio? Que novas maneiras de pensar e de conviver estão sendo elaboradas no mundo das telecomumicações e da informática? Enfrentando essas questões, compreendemos, com a ajuda de Lévy (1993), que está emergindo um novo conhecimento por simulação que os epistemologistas ainda não inventariaram. Vivemos hoje uma redistribuição da configuração do saber que se havia estabilizado com a generalização da impressão. $O$ ciberespaço é certamente um dos futuros da leitura e da escrita. No entanto, é preciso compreender que a sucessão da oralidade, da escrita e da informática, como modos fundamentais de gestão social do conhecimento, não se dá por simples substituição, mas antes por complexificação e deslocamentos de centros de gravidade. $\bigcirc$ saber oral e os gêneros de conhecimento fundados sobre a escrita ainda existem e irão continuar existindo sempre. Mas como vamos olhar a Internet e suas possibilidades de escrita? Não estaria a Internet integrando de uma maneira nova oralidade e escrita? Uma outra relação com o texto e com a escrita não estaria sendo possibilitada pela Internet?

Para Rocco (1999), o texto eletrônico da Internet constitui-se em um produto verbal diferente, característico de um novo tempo e veiculado por um novo suporte, que atua tanto sobre a natureza e feição dos textos quanto sobre os processos de apropriação e significação dos leitores. Trata-se, para a autora, de um texto híbrido, que, por escrito, lança mão de recursos da oralidade e de ícones, visando aproximar-se de uma conversação natural.

esboço dessa perspectiva histórica levou-nos à compreensão de que oralidade, escrita e impressão não são eras, não correspondem de uma forma simples a épocas determinadas. As três, a cada instante e a cada lugar, manifestam-se, misturando-se agora ao último pólo, a informática, surgida no final do milênio (Freitas, 2000).

Em seguida, discutimos sobre as possibilidades de a escrita contribuir para o desenvolvimento cognitivo, apoiados no pensamento de Vygotsky (1991, 1991a, 1987, 1996), Bakhtin (1985, 1988, 1992) e também de outros autores (Ong, 1982, 1998; Olson, 1997, 1998; Olson, Torrance, 1995)4. Finalmente, apoiados em Bakhtin ( 1985 ), situamos o gênero discursivo, abordando a questão teoricamente no âmbito escolar e da Internet. Que gêneros discursivos estão sendo usados na escrita escolar? A escrita na Internet está constituindo um novo gênero?

4. Para um maior aprofundamento da questão, ver Freitas, 2001. 
No aspecto mais prático, buscamos maior compreensão da própria escrita dos participantes do grupo de pesquisa. Esse aspecto foi trabalhado por meio de relatos compartilhados das histórias pessoais com a linguagem escrita e procurando o seu desenvolvimento mediante a construção de textos motivados pelas leituras feitas em razão da temática da pesquisa, anotações de campo e atas das reuniões. Estas últimas constituem-se em um instrumento, que tem acompanhado nossos trabalhos de pesquisa desde 1995, com uma dimensão formadora. Nelas o ato de escritura não se limita apenas ao registro dos fatos mas o pesquisador imprime a sua autoria, a sua forma de ver e compreender as diferentes situações experimentadas no processo do grupo. Acompanhando essa mesma lógica, organizamo-nos para que os pesquisadores ainda não iniciados passassem por uma experiência de uso da Internet. Para desenvolver a familiaridade com a Internet esta começou a ser usada entre os pesquisadores para atividades de pesquisa de textos na $m w w$ e, na medida do possível, intensificar a comunicação entre os membros da pesquisa via e-mail, criando também entre nós uma lista de grupo. Discutimos a viabilidade de uma home page sobre a pesquisa, para possibilitar o maior contato com os internautas. Finalmente, com o suporte de uma das pesquisadoras, foi criada a home page: wuw.lic.ufff.com.br ${ }^{5}$.

No entanto constatou-se que o novo objeto de estudo não permitia o aproveitamento da experiência acumulada com as pesquisas anteriores. A questão a ser investigada exigia novas estratégias e não estávamos seguros para determiná-las. Assim definimos que para um trabalho de campo mais produtivo seria bom iniciarmos a investigação de um período exploratório. Isso permitiria avaliar as ações, aprender com elas, definir os critérios para uma definitiva escolha dos sujeitos, indicando os instrumentos metodológicos e a sua forma de utilização. Precisávamos aprender, num ensaio investigativo, como nos aproximar do objeto de estudo pretendido.

Organizamos o período exploratório trabalhando com dois sujeitos: um aluno de escola particular com computador em casa e outro aluno de escola pública sem computador, mas usuário de um serviço de atendimento à comunidade oferecido pela Universidade Federal de Juiz de Fora.

5. Assim nossa pesquisa pode ser acessada por pessoas que não fazem parte do grupo mas contribuem com suas sugestões, indicações de fontes bibliográficas e discussões, o que amplia nosso conhecimento sobre o tema, integrando-nos com outros pesquisadores ou usuários da Internet. É interessante observar que até a data de 4.4 .02 a home page já havia recebido um total de 10.374 visitas. 
Foi muito útil esse estudo-piloto. Refletindo sobre as dificuldades encontradas, no seminário interno que encerrou a primeira fase da pesquisa, preparamonos para reestruturar a metodologia para a etapa seguinte. A análise dos relatórios apresentados pelos pesquisadores viabilizou várias conclusões em relação aos instrumentos e ao próprio processo metodológico empregado.

Uma das principais conclusões dizia respeito ao processo de escolha dos sujeitos. Querendo focalizar o usuário da Internet em seu ambiente, pela observação participante, deparamo-nos com uma dificuldade. Como escolher os sujeitos e como realizar essa observação? De acordo com Vygotsky (|99|) o estudo de situações fundamentalmente novas exigem inevitavelmente novos métodos de investigação e análise. Foi o que aconteceu, pois percebemos que a observação não poderia ser a usual, mas o novo meio exigia uma adequação dessa técnica. Deveríamos interagir com os potenciais sujeitos da pesquisa no interior de um espaço virtual, participando de chats, usando e-mails etc. Conscientes de que numa pesquisa qualitativa o movimento inicial deve ser o de aproximação, buscamos uma inserção no campo a ser investigado, visando compreender o que queríamos estudar, estabelecendo uma convivência com o novo meio, tornando-nos nós mesmos internautas. Assim, desejando desvelar essa nova realidade, ainda pouco vivenciada, percebemos que, para melhor compreendê-la, seria preciso partir de uma imersão mais profunda no mundo virtual ${ }^{6}$, convivendo com o próprio objeto de investigação. Navegamos por horas a fio, visitamos sites de nossos interesses e de possíveis interesses para os adolescentes, utilizamos o correio eletrônico como meio de comunicação.

Enfim, no período de março a julho de 2000, mergulhamos no trabalho de campo realizando o que se denomina observação virtual, interagindo com adolescentes em salas de bate-papo, em chats do MIRC ou da WEB, em listas de discussão e por e-mails. Dessa forma, empenhamo-nos em uma coleta de artefatos e de dados significativos, mas sem uma preocupação de definir sujeitos específicos. Isso provocou uma profunda discussão acerca da ética, pois, estaríamos interagindo com adolescentes via chats e e-mails sem explicitar a situação de pesquisa e o nosso

6. Apesar de no início da pesquisa termos realizado um treinamento em Internet e de todos já fazermos algum uso dela, a maioria dos pesquisadores não tinha ainda uma experiência específica com salas de bate-papo e com os diversos tipos de chats. Especialmente não estávamos habituados a "chatear" com adolescentes. Uma das bolsistas de iniciação científica, freqüentadora assídua de salas de bate-papo, teve um papel importante na iniciação dos outros elementos do grupo nesse meio virtual. 
papel de pesquisadores. Contudo, chegamos à conclusão de que o próprio nickname já garantiria o anonimato dos sujeitos.

A opção por essa observação virtual justificou-se pelo fato de não estarmos, assim, criando uma situação artificial de pesquisa, pois, interagindo com os internautas em seu meio natural poderíamos observá-los de forma completa e, simultaneamente, compreender sua escrita a partir do meio no qual estavam inseridos. Essa foi uma importante decisão tomada com base na análise da observação do projetopiloto que se mostrou artificial, inadequada e ineficiente.

Foi muito rico o período em que penetramos na corrente da linguagem dos internautas. A princípio nos sentimos "estranhos no ninho", ao iniciarmos nossa incursão pelos chats. Convivemos com termos próprios aos quais não estávamos acostumados, tivemos que adotar um nickname, conhecer e seguir as regras estabelecidas para a comunicação virtual. Fomos identificados pelos internautas como calouros e novatos pelo nosso modo de expressar tão diferente do deles. Era como se fôssemos aprendizes de uma nova língua. Aos poucos, penetrando na corrente dessa linguagem, fomos adotando os termos próprios, a forma específica de escrever, de teclar. Já não mais éramos estranhos e começávamos a fazer parte no novo grupo cultural.

Após cada sessão de interação via chat ou e-mail, o pesquisador gravava o seu conteúdo e escrevia uma nota de campo com suas reflexões sobre a experiência vivida. Em muitos desses relatos, nos diários de bordo produzidos durante o período da observação virtual, referimos nossas próprias transformações e algumas rejeições e barreiras no início do trabalho. A novidade do tema e as dificuldades iniciais desta etapa configuraram-se numa experiência interessante e desafiadora. Por muitas vezes enfrentamos o desejo de desistir, o medo de não conseguir. Mas a cada novo navegar interagíamos com essa escrita teclada e percebíamos suas peculiaridades. A cada reunião ouvíamos relatos de observações que deram certo, que trouxeram frutos, e o trabalho seguia. E a cada leitura nova, renovávamos os interesses e buscávamos aprofundar os conhecimentos sobre o foco de análise.

Essa imersão no meio virtual possibilitou-nos uma aproximação compreensiva do objeto de estudo - a construção/produção da escrita na Internet -, atentando para os aspectos da relação investigador-investigado, a especificidade da situação na qual emergiram os enunciados produzidos/construídos, assim como os sentidos que emergiram no processo de interlocução.

Aprendemos uma nova forma de observar, de coletar dados e artefatos. Foram características dessa nova forma: o enorme tempo gasto nessas interações 
via chats e e-mails com adolescentes e o próprio horário que, na maioria das vezes, invadia as madrugadas. Até a análise dos dados teve um caráter de especificidade, diante do volume extenso de dados acumulados no computador e gravados em nossos arquivos. Uma enormidade de folhas a ser impressa com as sessões de observação virtual que nos ajudaram a construir um respeitável banco de dados. $\bigcirc$ processo de definição de categorias tornou-se por isso muito mais complexo e demorado.

Foi pedido a cada pesquisador que construísse uma síntese do que colhera na observação virtual a partir dos artefatos impressos e das notas de campo elaboradas. A essa síntese foi dado o nome de memorando. Esses memorandos foram lidos e discutidos no grupo de pesquisa. Guiados por nossas questões orientadoras e pelos memorandos, procuramos fazer um recorte nos dados coletados, construindo um quadro esquemático que nos levou posteriormente à definição de três grandes categorias com suas respectivas subcategorias:

\section{O processo metodológico de pesquisa no ciberespaço}

2. A temática e o processo da escrita na Internet (o quê, por quê, para quê, para quem escrevem os adolescentes na Internet)

2.I O discurso escrito em e-mail: o adolescente, seus interesses e suas relações sociais

2.2 O discurso escrito em salas de bate-papo: o adolescente, seus interesses e suas relações sociais

\section{A construção do discurso escrito na Internet}

3. I O que é escrever teclando (oralidade/escrita, tempo/espaço, real/virtual, gêneros discursivos presentes, surgimento de novos gêneros)

3.2 Características da escrita: formas, códigos e recursos

3.3 Os enunciados de abordagem em salas de bate-papo

$3.4 \bigcirc$ nickname: recurso de comunicação ou estratégia de construção do eu? (Freitas, 200 la)

Foram elaborados textos, a partir das categorias definidas, nos quais se evidenciou nossa preocupação em compreender o processo de construção/produção da escrita na Internet pelos adolescentes pesquisados, relacionando-o ao contexto social, marcado pelas transformações trazidas pela presença das novas tecnologias.

A análise dos dados mostrou o quanto a escola está off-line, num mundo em que tudo está on-line. Os próprios internautas diferenciam o que produzem e vi- 
vem em ambos os espaços. Compreendemos então a nossa dificuldade de pesquisar, ao mesmo tempo, de forma integrada, a escrita na Internet e na escola. Assim, a falta de uma ponte entre o real e o virtual estava justificando as dificuldades em unilos, como havíamos experienciado no projeto-piloto. Por isso, centramo-nos, num primeiro momento, na análise da escrita de adolescentes na Internet, sem articulála diretamente à escrita da escola. Num segundo momento é que contatamos algumas das pessoas com as quais interagimos virtualmente, propondo que participassem da pesquisa por meio de encontros presenciais. Aceita essa proposta, cada pesquisador interagiu com um desses sujeitos em entrevistas presenciais e também via rede.

Fizemos uso da entrevista, em acordo com Bogdan e Biklen (1994), que a consideram o melhor instrumento de abordagem para o estudo de pessoas que partilham uma característica particular. Aquilo que partilham entre si revelar-se-á mais claramente quando cada um puder falar de suas perspectivas, mais do que quando observado em suas atividades. Foram, portanto, realizadas entrevistas com esses sujeitos contatados com a mediação da Internet. Entendemos a entrevista como produção de linguagem, uma vez que esta se realiza pela interação verbal, cuja realidade fundamental é o seu caráter dialógico. Para Bakhtin ( 1992), o enunciado é a unidade real da comunicação discursiva. Vemos a entrevista como um espaço de produção de enunciados que se alternam e que constroem um sentido na interação das pessoas envolvidas. As entrevistas foram gravadas em vídeo e ou áudio e posteriormente transcritas pelos próprios pesquisadores.

Para complementar os dados e atender à especificidade do estudo, foi importante colher com os adolescentes artefatos de sua produção/construção de escrita na Internet bem como daquela realizada na e para a escola na qual estudam. Percebemos que assim focalizamos também a escrita da e na escola de uma forma mais natural, podendo estabelecer suas relações com a que produzem na Internet. A escola foi, portanto, vista a partir da voz e da escrita de seus alunos e não das observações em salas de aulas, que foram desencorajadas pelo projeto-piloto por não se mostrarem adequadas para o objetivo da investigação.

A análise das entrevistas e dos respectivos artefatos, colhidos entre os participantes, permitiu um aprofundamento maior da questão pesquisada, dando oportunidade também a uma reflexão em relação ao trabalho da escola, com subsídios para a formação de professores no que se refere ao trabalho com a leitura/escrita num tempo em que novas tecnologias estão presentes.

Estamos conscientes de que todo esse processo metodológico permitiu focalizar melhor nosso objeto de estudo, ampliando o enfoque teórico que, articula- 
do ao papel ativo do investigador e dos participantes, conduziu a um novo conhecimento em relação à construção/produção da escrita de adolescentes na Internet e na escola. O percurso relatado permite perceber como, nesta pesquisa, o processo foi mais importante do que o produto e de como os pesquisadores se ressignificaram e aprenderam com o desenrolar do próprio trabalho. É nesse sentido que podemos afirmar que a pesquisa qualitativa orientada pela abordagem sócio-histórica se constitui em uma instância de aprendizagem e de produção de conhecimento.

\section{REFERÊNCIAS BIBLIOGRÁFICAS}

AMORIM, M. O Detetive e o pesquisador. Documenta. Eicos/Cátedra Unesco de Desenvolvimento Durável/UFJF. v. 6, n.8, p. 127-141, 1997.

ANDRÉ, M. E. D. A. Etnografia da prática escolar. Campinas: Papirus, 1995.

BAKHTIN, M. Estética da criação verbal. São Paulo: Martins Fontes, 1992.

. Estética de la creación verbal. Buenos Aires: Siglo Veintiuno Argentina Editores, 1985.

- [Volochinov, V.] Marxismo e filosofia da linguagem. São Paulo: Hucitec, 1988.

BOGDAN, R.; BIKLEN, S. Investigação qualitativa em educação. Porto: Porto Editora, 1994.

FONSECA, C. Quando cada caso não é um caso: pesquisa etnográfica e educação. Revista Brasileira de Educação, n. 10, p. 58-78, 1999.

FREITAS, M. T. A. Bakhtin e a psicologia. In: FARACO, C.A. et al. Diálogos com Bakhtin. Curitiba: Editora da UFPR, 1996. p. 165-187.

. A Escrita de adolescentes na Internet. Psicologia Clínica, v. 12 n.2, p. 171-188, 2001.

. Escrita teclada, uma nova forma de escrever? In: ANPED, Reunião Anual, 23: anais...Caxambu, 2000. [Anais Eletrônicos]

. O Processo metodológico de pesquisa: uma instância de aprendizagem. 200 la. [Relatório de pesquisa para o CNPq]

LÉVY, P. As Tecnologias da inteligência. Rio de Janeiro: Editora 34, 1993.

LURIA, A. R. Desenvo/vimento cognitivo: seus fundamentos sociais e culturais. São Paulo: Ícone, 1990.

. Uno Sguardo sul passato: considerazioni retrospettive sulla vita di uno psicologo sovietico. Firenze: Giunti Barbèra, 1983. 
OLIVEIRA, M. K. Três questões sobre desenvolvimento conceitual. In: OLIVEIRA, M. B.; OLIVEIRA, M. K. (orgs.). Investigações cognitivas. Porto Alegre: Artes Médicas, 1999. p. 55-64.

OLSON, D. R. O Mundo no papel. São Paulo: Ática, 1997.

. A Escrita e a mente. In: WERTSCH, J. V. et al. Estudos socioculturais da mente. Porto Alegre: Artes Médicas, 1998. p. 89-। II.

OLSON, D. R.; TORRANCE, N. Cultura escrita e oralidade. São Paulo: Ática, 1995.

ONG, W. J. Oralidade e cultura escrita. Campinas: Papirus: 1998.

. Orality and literacy: the tecnologizing of the word. Londres: Meuthen, 1982.

REY, F. G. La Investigacion cualitativa en psicología. São Paulo. Educ, 1999.

ROCCO, M. T. F. Entre a oralidade e a escrita: reflexões esparsas. In: DIETZSCH, M. J. Espaços da linguagem na educação. São Paulo: Humanitas, 1999. p.85-I 15.

SOUZA, S. J.; CASTRO, L. R. Pesquisando com crianças: subjetividade infantil, dialogismo e gênero discursivo. Psicologia Clínica-Pós Graduação e Pesquisa. v.9, n.9, p.83- I I 5, 1 997/8.

VYGOTSKY, L. S. A Formação social da mente. São Paulo: Martins Fontes, 1991.

. História del desarrollo de las funciones psíquicas superiores. Habana: Editorial Científico Técnica, 1987. . Obras escogidas. Madrid: Visor, 1996. v. 4. . Pensamento e linguagem. São Paulo: Martins Fontes, 1991a. 